\title{
Memórias de infância: possibilidades e vivências no processo criativo docente
}

\author{
Vanessa Freitag ${ }^{1}$ \\ Doutoranda pelo CIESAS - Centro de Investigaciones y Estudios en Antropología Social - \\ linha de pesquisa em Antropología Cultural e Identidades Contemporáneas (Guadalajara- \\ México). Mestre em Educação, com ênfase em Educação e Artes pela Universidade Federal de \\ Santa Maria (UFSM-RS). Tem experiência na área de Artes, com ênfase em Poéticas Visuais e \\ Ensino da Arte, atuando principalmente nos seguintes temas: arte contemporânea, memória e \\ processo de criação, formação de professores em Artes Visuais. \\ E-mail: vanessa.freitag@gmail.com
}

Resumo: O referido artigo apresenta como objetivo principal investigar, descrever e analisar as memórias de infância relatadas por três professoras de Artes Visuais da Casa de Cultura de Santa Maria-RS, e, através destas, possibilitar vivências e reflexões acerca do processo criativo docente delas. A metodologia caracterizou-se por uma abordagem qualitativa, cuja linha metodológica abordou a História de Vida Tópica (memórias de infância). Os dados foram coletados a partir de entrevistas semiestruturadas, da análise documental e do diário de campo como forma de registro dos pensamentos e da produção de cada professora. Os encontros, cerca de dez ao todo, foram realizados na própria Casa de Cultura.

Palavras-chave: memórias de infância, história de vida, processo criativo docente, arte, ensino de artes.
Abstract: The present paper it had as main objective to investigate, to describe and to analyze the childhood memoirs told by three teachers of Visual Arts at the House of Culture of Santa Maria-RS and through these, to develop the teaching creative process of them. Therefore, the methodology was characterized by a qualitative approach whose History of Topical Life (childhood memoirs) was approached as a methodological line. Data were collected starting from semistructured interviews, documental analysis and field diary as form of recording of the thoughts and of each teacher's production. About ten meetings were accomplished at the House of Culture.

Keywords: childhood memoirs, life history, educational creative process, art, art teaching.

Em minha trajetória profissional, memórias e histórias de infância marcaram significativamente as produções e pesquisas no campo das Artes Visuais e continuam sendo foco de meus estudos no Ensino de Arte, ou seja, como professora. Algumas dessas memórias evidenciaram, especialmente, as minhas vivências no contexto rural (lembranças das plantações

Recebido: 07.04.2008

Aprovado: 07.05 .2008

1. Disponível em: $<$ http://lattes.cnpq. br/2359848414773274>. 
2. GALZERANI, Maria Carolina Bovério. Memória história e (re)invenção educacional: uma tessitura coletiva na escola pública. In: MENEZES, Maria Cristina (Org.). Educação, memória, história: possibilidades, leituras. Campinas: Mercado das Letras, 2004. p. 295

3. A Casa de Cultura, também conhecida como EMAET (Escola Municipal de Artes Eduardo Trevisan), localiza-se na cidade de Santa Maria-RS e desde sua fundação, em 1982, oferece cursos e aulas de Artes Visuais, Teatro e Música para toda a comunidade interessada.

4. LE GOFF, Jacques. História e memória. Campinas: Unicamp, 2003. comunicação \& educação • Ano XIV • Número 1 • jan/abr 2009

e das colheitas, das sementes, do cheiro da terra molhada, das flores, dos ruídos da natureza), entre outras. Portanto, imagens latentes e grávidas de sentidos, tornando afetivo o olhar sobre momentos e histórias partilhadas com um grupo numa fase singular de minha vida.

Acredito que nossas memórias nos ajudem a mostrar que temos uma trajetória e que somos responsáveis por ela muitas vezes, bem como pelas situações enfrentadas ao longo do tempo, tais como a saudade, a perda e as conquistas, a instabilidade de tempos, espaços, lugares e das relações afetivas, num mundo em constante transformação. Estudar a memória implica estar sempre remexendo fatos ou momentos sutis da nossa história e vendo aí possibilidades de agir sobre o presente.

"Rememorar é partir de indagações presentes, para trazer o passado vivido como opção de busca atenciosa, em relação aos rumos a serem construídos no presente e no futuro. Não se trata de apenas não esquecer o passado mas agir sobre o presente." 2

Nesse sentido, o artigo que apresento traz algumas referências teóricas que discutem a relevância da memória e suas possibilidades no processo criativo das docentes, objetivando contribuir na formação continuada delas. O foco da investigação realizada foi a análise das memórias de infância relatadas por algumas educadoras em Artes Visuais da Casa de Cultura ${ }^{3}$, em que se teceram possíveis entrelaçamentos com as referências da arte contemporânea que problematizam questões como identidade e memória.

Portanto, o trabalho que apresento é um recorte de minha dissertação de mestrado em Educação, caracterizando-se como uma pesquisa qualitativa cujos encontros aconteceram através de entrevistas semiestruturadas, com as falas e imagens gravadas e registradas, além do diário de campo por mim utilizado e também pelas participantes da pesquisa. Ao final dos encontros, as professoras desenvolveram um trabalho plástico-visual construído em etapas e, posteriormente, realizaram uma exposição coletiva na cidade.

\section{A MEMÓRIA EM MOVIMENTO}

Nas últimas décadas, muitos estudos têm contribuído para se pensar o conceito e a importância das memórias no campo das Ciências Sociais, História, Antropologia, Educação, Artes, entre outras's. Estudar a memória acarreta trazer à tona informações e imagens cuidadosamente armazenadas pelas pessoas e evocadas através de narrativas escritas ou orais.

Em muitos momentos, essas lembranças podem gerar sentimentos de nostalgia ou angústia, na qual experiências carregadas de sentidos são trazidas para o instante que se revive ao se recordar. No entanto, cabe mencionar que a memória é algo vivo e móvel, está constantemente presente na constituição social do sujeito e na forma como se analisam e se ressignificam essas histórias: "Os estudos da memória, especificamente, estão auxiliando 
tanto as análises acerca do vivido presente/cotidiano quanto de fatos e tempos passados; estão se apresentando, em sua maior parte, como uma forma de fazer o tempo passado se presentificar analítica e oralmente"

Assim, talvez sejam nossas memórias aquelas lembranças que nos revelam fragmentos de experiências vividas realmente ou, ainda, histórias condicionadas consciente/inconscientemente na reinvenção de fatos como se fossem verdades, pois, "esquecer um período da vida é perder o contato com os que então nos rodeavam”.

Referir-nos à memória significa entrelaçar a noção de tempo vivido, recordado, com aquilo que se oculta ou se esquece. Lembrar de algo implica estar afetivamente envolvido com a história que é rememorada, e aquilo que esquecemos (e que faz parte da memória) se deve, muitas vezes, ao nosso desencontro no interior de um grupo, ou seja, quando não nos sentimos parte ou inteiramente presente no coletivo ou quando estamos menos interessados por algo acontecido, principalmente com relação às memórias de infância. Outra particularidade da memória diz respeito às percepções que construímos sobre uma experiência recordada: duas ou mais pessoas podem viver uma mesma situação ou uma mesma história, mas lembrá-la (e até mesmo esquecê-la) de modo particular quando evocá-la. E, ainda, contar a mesma história vivida inúmeras vezes, sempre de forma diferente.

Partindo desse pressuposto, toda memória (mesmo aquela que denominamos como individual) é produto dessas relações sociais que mantivemos, pois que não nascemos determinados, mas vamos nos formando mediante as interações em que a linguagem/comunicação, entrelaçada pela afetividade, participa ativamente desse processo, no qual "a base social/coletiva da memória constitui-se na família, nas classes, nos grupos de referência (escola, empresa, partido, etnia, nação...), na religião, na tradição, dentre outras"7.

Segundo Tedesco, a importância da família na infância seria uma das bases ou estruturas para as futuras relações sociais que teremos. Com isso, quando adultos, passaremos a fazer parte de diferentes quadros, ou seja, mudança de lugar, de profissão, de família, de relações afetivas, que geram uma série de fatores que se entrecruzam e influenciam nossa trajetória, nosso modo de pensar, nossos imaginários e memórias.

Contudo, para o presente estudo, os encontros com as professoras de Artes Visuais aconteceram mediados por algumas temáticas relativas às memórias infantis, tais como: as lembranças escolares, os esconderijos, as cores, os cheiros, gostos e sabores da infância, brinquedos e brincadeiras, ligações familiares, bem como as relações da memória com a arte.

\section{MEMÓRIA E ARTE: RELAÇÕES POSSÍVEIS}

A questão da memória, individual ou coletiva, também vem sendo significativamente pensada nas poéticas visuais. Muitos artistas lançam mão de sua intimidade, de suas experiências e vivências, como referência
5. TEDESCO, João Carlos. Nas cercanias da memória: temporalidade, experiência e narração. Passo Fundo: UPF, 2004. p. 29

6. HALBWACHS, Maurice. A memória coletiva. São Paulo: Centauro, 2006. p. 37.

7. TEDESCO, João Carlos. Nas cercanias da memória, cit., p. 156. 
8. CANTON, Katia. Novíssima arte brasileira: guia de tendências. São Paulo: Iluminuras, 2001.

9. Ibid., p. 43.

10. CAUQUELIN, Anne. Arte contemporânea: uma introdução. São Paulo: Martins Fontes, 2005.

11. ARCHER, Michael. Arte contemporânea: uma história concisa. São Paulo: Martins Fontes, 2001.

12. DANTO, Arthur C. Após o fim da arte: a arte contemporânea $e$ os limites da história. São Paulo: Odysseus Editora, 2006. p. 16. estética ou conceitual para as produções visuais, na tentativa de resgatar e compreender, muitas vezes, suas identidades.

Por esse motivo, Canton ${ }^{8}$ sugere algumas tendências na produção artística contemporânea que abrangem discursos sobre a fragilidade e estranheza do corpo, a identidade, a abordagem constante das tênues fronteiras entre os espaços públicos e privados, o contexto urbano, a diversidade cultural, o gênero, o uso de aparatos tecnológicos e digitais em nossas vidas e, logicamente, a memória, dentro dos questionamentos frequentes de alguns trabalhos contemporâneos. A mesma autora argumenta que "a memória, física e psíquica, garantia maior de nossa condição humana, torna-se também uma das principais molduras da criação artística contemporânea"9. Porém, as tendências citadas apenas sinalizam as propostas constantemente trabalhadas e, assim, propõem refletir e compreender a arte contemporânea encarada ainda por muitos como um enigma.

Atentamos para o fato de que a arte contemporânea, para Cauquelin ${ }^{10}$ e $\operatorname{Archer}^{11}$, tem suas reminiscências por volta da década de 1960, causando rupturas e estranhamentos devido ao uso de elementos e referências do nosso cotidiano nas apropriações artísticas. Por isso, muito do que foi produzido ou criado nas últimas décadas desafia a hegemonia de linguagens tradicionais (como a pintura, a escultura, o desenho etc.), além de causar inquietações no espectador que se depara com objetos do cotidiano legitimados como arte. E, com isso, os artistas e seus trabalhos instauram, na maioria dos casos, desconforto ou julgamentos que negam ser artístico esse mesmo objeto ou obra.

Todo e qualquer material, referência ou conceito são potencialmente artísticos, pois o que legitima a obra de arte é o contexto em que esta se encontra, ou seja, museus e galerias. Nesse sentido, os materiais, a forma/organização, a temática, os recursos utilizados, a formação do artista não conseguem, por si só, legitimar nem o artista nem a obra de arte, pois "o nosso é um momento, pelo menos (e talvez unicamente) na arte, de profundo pluralismo e total tolerância. Nada está excluído"12 e deve, particularmente, encontrar-se inserido no sistema. A memória como referência, conceito ou matéria da arte é abordada no contexto artístico como um viés para problematizar a efemeridade de nosso corpo, de nossa vida, de nossa história, de nossas relações afetivas com o outro, de nossos discursos sobre identidade/diferença, sobre espaços e contextos públicos e privados. Instigamos nossos olhares acerca da produção visual, imbuídos de sentidos e significados, na tentativa de fomentar outros olhares possíveis.

Assim, penso que esta investigação foi um modo de incitar a problematização das educadoras sobre seus próprios processos criativos, seja em arte, seja, especialmente, enquanto docentes em arte: como se veem como produtoras e professoras de arte? Que importância ou diferença isso faz em suas práticas educativas? Como suas memórias contribuem nesse processo? 
A pesquisa aqui apresentada também visou refletir sobre o processo criativo docente, propondo retomar ou incentivar nas docentes o pensamento poético, a pesquisa em arte e as reflexões suscitadas para a prática educativa delas.

\section{O PROCESSO CRIATIVO DOCENTE}

Acredito como imprescindível nos cursos de formação de professores (inicial e continuada) a construção de saberes e conhecimentos das disciplinas e conteúdos pedagógicos aprendidos e ensinados, que se preocupe em proporcionar ou instigar nos professores a autonomia, a pesquisa, a criatividade e a imaginação, e em como promovê-las ou contemplá-las dentro da sala de aula e demais instituições educativas. Loponte ${ }^{13}$ questiona se haveria espaço para a invenção e para a criação na docência, e como nos inventaríamos enquanto docentes? A partir das memórias relatadas pelas professoras de Artes Visuais durante os nossos encontros, os diálogos foram gerando pensamentos e imagens na gestação de ideias para a produção de um trabalho visual que incentivasse a poética de cada docente, constituindo, com isso, um prazeroso desafio.

No entanto, não me propus reiterar que o trabalho artístico fosse tão ou mais relevante que a profissão de professor, muito menos o fato de que, para ser professor de arte, necessite, obrigatoriamente, ser um artista. São momentos distintos, porém unidos ou tecidos pela arte. Pensei em articular essas duas posturas profissionais para refletir sobre o Ensino de Artes e, especialmente, a prática educativa dessas profissionais.

Uma docência que se faz "artista" pode ser aquela que assume o seu trabalho como um processo de ir e vir, de rascunhar, rabiscar, voltar a desenhar-se. Um trabalho sobre si mesmo que não se faz sozinho. As relações intersubjetivas são fundamentais para a formação docente. Não há estética de si mesmo na solidão. A formação docente é uma ação compartilhada com pares, grupos diversos (dentro ou fora da escola) ${ }^{14}$.

Ao entrelaçar a poética do artista, no que concerne ao processo de criação de um trabalho ou quando pensa nas inúmeras possibilidades e desdobramentos de suas obras, com o pensar e refletir do professor acerca de suas pesquisas e práticas em sala de aula, estaríamos falando em processo criativo docente?

Visando a isso, acredito que os educadores contemporâneos poderiam desenvolver uma postura inquieta, inconformada, reflexiva, de um pesquisador interessado em modificar sua prática, começando pelos materiais e metodologias que utiliza cotidianamente ou pela forma como aborda e questiona os estudantes em sala de aula, e quando compartilha as dificuldades e problemas no trabalho com seus colegas. E muitas vezes, são profissionais extremamente interessados pela mudança, mas não sabem como
13. LOPONTE, Luciana Grupelli. Arte da docência em arte: desafios contemporâneos. In: OLIVEIRA, Marilda Oliveira de (Org.). Arte, educação e cultura. Santa Maria: Ed. da UFSM, 2007. p. 231-249.

14. Ibid., p. 236. 
fazê-la e por que caminhos começar a agir. O processo criativo docente se caracterizaria por estar sempre em processo, em devir, sendo e se fazendo, cuja coadjuvante desse trajeto se denominaria incerteza, assim como o artista que cria sem saber ao certo o resultado final de seu trabalho e, por isso mesmo, está sempre na procura. Talvez seja instigante o desafio de pensar em uma educação mais inventiva, tanto pela forma como se ensina ou pelos jeitos que se aprende, tendo em vista as inúmeras dificuldades, mas também possibilidades, que permeiam atualmente o cotidiano do educador.

O principal problema que hoje enfrentam nossas escolas e universidades é a narrativa dominante sobre a educação na qual se inserem e suas dificuldades em mudá-la. As narrativas são formas de estabelecer a maneira como há de ser pensada e vivida a experiência. Uma forma de narrativa muito poderosa no terreno educativo é aquela que tende à naturalização: "as coisas são como são e não podem ser pensadas de outra maneira" ${ }^{" 5}$.

O professor de Artes Visuais, imerso em sua rotina diária de trabalho, acaba renunciando, muitas vezes, ao prazer e às descobertas que implica a pesquisa plástica, a qual possibilita, inclusive, usar sua prática artística (quando consegue ter uma) para aproximar um pouco mais os estudantes da realidade ou do processo artístico em si. Além disso, creio que nem todos os educadores se sentem à vontade ou têm disponibilidade (devido à intensa carga horária) para manter e expor um trabalho próprio. Por isso mesmo, as memórias de cada participante da pesquisa sobre suas vivências objetivaram fazer com que refletissem acerca de suas posturas enquanto educadoras, criadoras e propositoras, ressignificando as histórias de vida, as suas memórias, na perspectiva de que se percebessem como professores pesquisadores.

O processo criativo docente significa, também, os olhares e sentidos construídos pelo professor sobre sua profissão, a forma como pesquisa e investiga sua prática educativa, a necessidade de constante reflexão sobre suas ações na sala de aula, além da formação continuada, que possibilita rever e desacomodar pensamentos arragaidos sobre o que pensa e faz. Penso que o processo criativo docente também abraçaria algumas dessas esferas trazidas no trabalho apresentado, no que concerne às suas trajetórias pessoais e profissionais. As histórias das professoras, evocadas a partir das memórias e lembranças sobre diferentes aspectos da vida pessoal na infância e também acerca da vida profissional, propiciaram que elas reconhecessem a importância de suas passagens, de suas experiências e conquistas, pois são pessoas e, como tais, produzem conhecimentos e trajetórias vividas e ainda por devir; pessoas que sentem, que se alegram e sofrem, que pensam

15. HERNÁNDEZ, Fernando. Catadores da cultura visual: proposta para uma nova narrativa educacional. Porto Alegre: Mediação, 2007. p. 11. e questionam.

As nossas lembranças são reconstruções de histórias vividas e, por isso mesmo, importantes para se analisar até que ponto recordamos alguns momentos e esquecemos outros. Contudo, rememorar constitui uma ação comprometida com as experiências que construímos. Nosso olhar e interpre- 
tação sobre tais experiências direcionam ou influenciam significativamente os rumos e as trajetórias que construímos ao longo da vida; "rememorar é partir de indagações presentes, para trazer o passado vivido como opção de busca atenciosa, em relação aos rumos a serem construídos no presente e no futuro" ${ }^{16}$.O ato de evocar memórias e ressignificá-las possibilita que o professor pense sobre os meios e os modos de agir quanto às suas práticas pedagógicas, e que não havia percebido anteriormente. Também propicia que um distanciamento sobre suas próprias experiências sejam tomadas e, assim, analisadas sobre outro prisma, outro olhar.

"À medida que eles pensam mais sobre sua história de vida, eles saem desse lugar ao qual estiveram presos e se dão conta das fronteiras que gostariam de atravessar e, ao assim fazer, refletem sobre os tipos de cruzamentos de fronteiras que os estudantes estão atravessando." ${ }^{17}$

Sendo assim, pensar a prática pedagógica do professor, levando em consideração sua bagagem e trajetória, significa articular distintos saberes e desafios que engendram o trabalho e a profissão em realidades tão específicas e paradoxais do seu cotidiano. Pensar sobre a prática educativa, hoje, implica refletir as condições de trabalho e a imersão do profissional no mundo contemporâneo em que vivemos, já que "a sobrevivência de certos profissionais e até a de sua profissão está profundamente vinculada à possibilidade de uma formação contínua"18. E, nesse processo, abarcaria a formação continuada e a postura crítica e investigativa do professor.

\section{BREVES CONSIDERAÇÕES}

O resgate acerca das memórias de infância das professoras foi muito sutil, porque não estavam habituadas a uma prática como esta e, talvez, muitos de nós não estejamos. O olhar cuidadoso sobre suas memórias foi rememorado pelas escritas e falas incentivadas ao longo da pesquisa, pelo exercício e a prática de contar suas vidas, as experiências mais significativas de um tempo em que foram crianças, mas, também, sobre suas escolhas profissionais e como atuam enquanto professoras, o que pensam, o que fazem e como, suas expectativas e dificuldades. Essa pesquisa me fez acreditar ainda mais na importância da formação contínua para a vida profissional dos professores. Muitos profissionais também têm ciência da relevância dessa formação para suas práticas em sala de aula; no entanto, nem sempre conseguem articular o conhecimento produzido na teoria com a prática no interior da escola.

A pesquisa também me fez pensar na importância de conhecer e refletir sobre as memórias e histórias das professoras, pois cada um de nós constrói e significa a própria vida e trabalho de modo subjetivo e distinto. E isso pode ser refletido na maneira como lidamos com nossa profissão, como tratamos nossa área de conhecimento e estudos, nossos alunos e
16. GALZERANI, Maria Carolina Bovério. Memória, história e (re)invenção educacional: uma tessitura coletiva na escola pública. In: MENEZES, Maria Cristina (Org.). Educação, memória, história, cit., p. 295.

17. MARTINS, Raimundo; TOURINHO, Irene (Orgs.). Ivor Goodson: políticas do conhecimento - vida e trabalho docente entre saberes e instituições. Goiânia: Programa de Pós-Graduação em Cultura Visual, 2007. p. 59 (Coleção Desenrêdos).

18. GARRIDO, Elsa; PIMENTA, Selma Garrido; MOURA, Manoel Oriosvaldo de. A pesquisa colaborativa na escola como abordagem facilitadora para o desenvolvimento da profissão do professor. In: MARIN, Alda Junqueira. Educação continuada: reflexões, alternativas. Campinas: Papirus, 2000. p. 89. 
comunicação \& educação • Ano XIV • Número 1 • jan/abr 2009

colegas, nossas relações afetivas e pessoais. Até que ponto essas vivências direcionam olhares sobre a vida atual? Vai depender da forma como refletimos algumas de nossas vivências em particular, levando em conta o contexto social, o qual contribui para que algumas das experiências sejam mais enfatizadas que outras.

\section{REFERÊNCIAS BIBLIOGRÁFICAS}

ARCHER, Michael. Arte contemporânea: uma história concisa. São Paulo: Martins Fontes, 2001.

CANTON, Katia. Novíssima arte brasileira: guia de tendências. São Paulo: Iluminuras, 2001.

CAUQUELIN, Anne. Arte contemporânea: uma introdução. São Paulo: Martins Fontes, 2005.

DANTO, Arthur C. Após o fim da arte: a arte contemporânea e os limites da história. São Paulo: Odysseus Editora, 2006.

GALZERANI, Maria Carolina Bovério. Memória, história e (re)invenção educacional: uma tessitura coletiva na escola pública. In: MENEZES, Maria Cristina (Org.). Educação, memória, história: possibilidades, leituras. Campinas: Mercado das Letras, 2004.

GARRIDO, Elsa; PIMENTA, Selma Garrido; MOURA, Manoel Oriosvaldo de. A pesquisa colaborativa na escola como abordagem facilitadora para o desenvolvimento da profissão do professor. In: MARIN, Alda Junqueira. Educação continuada: reflexões, alternativas. Campinas: Papirus, 2000.

HALBWACHS, Maurice. A memória coletiva. São Paulo: Centauro, 2006.

HERNÁNDEZ, Fernando. Catadores da cultura visual: proposta para uma nova narrativa educacional. Porto Alegre: Mediação, 2007.

LE GOFF, Jacques. História e memória. Campinas: Unicamp, 2003.

LOPONTE, Luciana Grupelli. Arte da docência em arte: desafios contemporâneos. In: OLIVEIRA, Marilda Oliveira de (Org.). Arte, educação e cultura. Santa Maria: Ed. da UFSM, 2007.

MARTINS, Raimundo; TOURINHO, Irene (Orgs.). Ivor Goodson: políticas do conhecimento - vida e trabalho docente entre saberes e instituições. Goiânia: Programa de Pós-Graduação em Cultura Visual, 2007. (Coleção Desenrêdos).

TEDESCO, João Carlos. Nas cercanias da memória: temporalidade, experiência e narração. Passo Fundo: UPF, 2004. 